\title{
Effect of sol-gel method on structural and electron magnetic resonance properties of $\mathrm{Pr}_{0.6} \mathrm{Sr}_{0.4} \mathrm{MnO}_{3}$ manganite
}

\author{
R. Thaljaoui ${ }^{1 a, b, c}$, W. Boujelben ${ }^{a}$, M. Pękała ${ }^{b}$, J. Szydłowska $^{c}$ and A. Cheikhrouhou ${ }^{\text {a, }}$ \\ ${ }^{a}$ Laboratoire de Physique des Matériaux, Faculté des Sciences de Sfax, B. P. 1171, 3000 Sfax \\ Tunisia \\ ${ }^{\mathrm{b}}$ Faculty of Physics, Warsaw University of Technology, Koszykowa 75, 00-662 Warsaw, Poland. \\ ${ }^{\mathrm{c}}$ Department of Chemistry, University of Warsaw, Al. Zwirki i Wigury 101, 02-089, Warsaw, \\ Poland. \\ ${ }^{\mathrm{d}}$ Institut NEEL, CNRS, B. P.166, 38042 Grenoble cedex 9, France
}

\begin{abstract}
Structural and electron magnetic resonance studies in a broad temperature range are reported for $\mathrm{Pr}_{0.6} \mathrm{Sr}_{0.4} \mathrm{MnO}_{3}$ manganite synthesized by sol-gel method. Temperature dependence of magnetic resonance spectra is analyzed in the paramagnetic state and compared to similar systems. Using the temperature variation of signal intensity the activation energy is calculated.
\end{abstract}

\section{Introduction}

Perovskite manganites $\left(\mathrm{ABO}_{3}\right)$ with general formula $\mathrm{R}_{1-\mathrm{x}} \mathrm{A}_{\mathrm{x}} \mathrm{MnO}_{3}(\mathrm{R}=\mathrm{La}, \mathrm{Pr}$ etc. and $\mathrm{A}=\mathrm{Ca}$, Sr etc.,) have attracted much attention for interesting magnetic refrigeration based on the magnetocaloric effect [1]. Therefore, the materials with large magnetocaloric effect are actively searched and examined [2] on their higher energy efficiency and environmental friendliness superior to the conventional vapor-compression-based refrigeration. The discovery of the large magnetocaloric effect in the hole-doped perovskite manganites $[3,4]$ as well as the observation of colossal magnetoresistance effect [5] in these materials, have attracted intensive interest [6-9]. The origin of the ferromagnetic state and metallicity has been explained on the basis of the double exchange (DE) and superexchange (SE) mechanisms. In many studies, it has been shown that the strength of DE and SE interactions in manganites is very sensitive to the variation of the average ionic radius of the Asite or Mn-site ions and the carrier density controlled by the $\mathrm{Mn}^{3+} / \mathrm{Mn}^{4+}$ ratio [10] . In previous work we have reported the electron magnetic resonance of $\operatorname{Pr}_{0.6} \mathrm{Sr}_{0.4} \mathrm{MnO}_{3}$ synthesized by conventional solid state method [11]. In order to understand the effect of the elaboration method on physical properties, the present work reports the properties of $\operatorname{Pr}_{0.6} \mathrm{Sr}_{0.4} \mathrm{MnO}_{3}$ sample elaborated by sol gel method.

\footnotetext{
1 e-mail : rachidthaljaoui@yahoo.fr
} 


\section{Experimental techniques}

$\mathrm{Pr}_{0.6} \mathrm{Sr}_{0.4} \mathrm{MnO}_{3}$ manganite with nanometer size crystallites was prepared by the sol-gel technique. Stoichiometric amounts of $\mathrm{Pr}_{6} \mathrm{O}_{11}, \mathrm{SrCO}_{3}$ and $\mathrm{Mn}_{2} \mathrm{O}_{3}$, were dissolved in minimal amount of nitric acid to obtain a clear pink solution. Suitable amount of citric acid (CA) was employed as complexation agent (1.5 mol of citric acid corresponds to $1 \mathrm{~mol}$ of metal cation). The resulting mixture was well magnetically stirred for $2 \mathrm{~h}$ in order to ensure complete dissolution of citric acid and to obtain stable metal-CA complexes. At this stage, the ethylene glycol (EG) was added to the solution as chelating agent. Then, the temperature was slowly increased to $90^{\circ} \mathrm{C}$ under constant stirring for about $4 \mathrm{~h}$ to evaporate the excess solvent and to accelerate the poly-etherification reaction between CA and EG. When the solvent in the system was completely evaporated, a homogeneous red resin with a glassy appearance was obtained. This resin was then dried at $150^{\circ} \mathrm{C}$ for about $6 \mathrm{~h}$ to evaporate the nitrogen and obtain a black fine powder which was then crushed and heated in air at $300^{\circ} \mathrm{C}$ before sintering at various temperatures $\left(400^{\circ} \mathrm{C}-800^{\circ} \mathrm{C}\right)$ for $6 \mathrm{~h}$ hours. After cooling, the sample was pressed into a pellet (of about $1 \mathrm{~mm}$ thickness and $13 \mathrm{~mm}$ diameter), and then sintered at 900 and $1000^{\circ} \mathrm{C}$ for $12 \mathrm{~h}$ in air with intermediate regrinding and repelleting. Phase purity, homogeneity and cell dimensions were determined by powder X-ray diffraction at room temperature. Structural analysis was made using the standard Rielveld technique [12, 13]. Electron magnetic resonance measurements were performed with a Bruker spectrometer, operating at $9.44 \mathrm{GHz}(\mathrm{X}$ band).

\section{Structural studies}

The room-temperature $\mathrm{X}$-ray diffraction pattern of $\operatorname{Pr}_{0.6} \mathrm{Sr}_{0.4} \mathrm{MnO}_{3}$ shown in Figure 1 indicates that our sample has a single phase and can be indexed in the orthorhombic structure with Pnma space group.

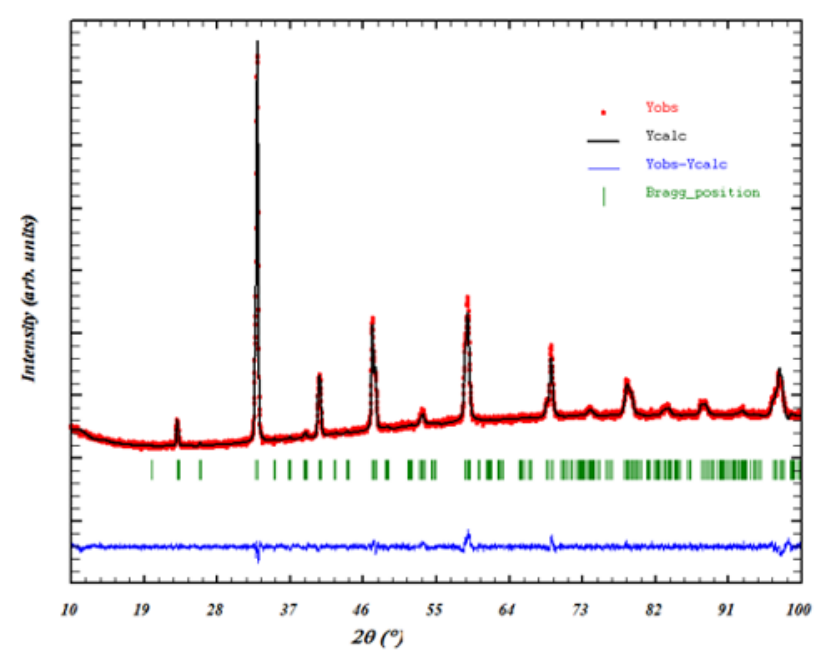

Fig. 1. Room - temperature X-ray diffraction pattern and refinement of $\operatorname{Pr}_{0.6} \mathrm{Sr}_{0.4} \mathrm{MnO}_{3}$ manganite

The structural parameters were refined by the standard Rietveld technique. The quality of the refinement is evaluated through the indicator $\chi^{2}$ equal to 1.59 . Lattice parameters are found to be equal to $a=5.4156(1) \AA, b=7.6540(7) \AA$ and $c=5.4709(5) \AA$, the unit cell volume is equal to $227.436(4) \AA^{3}$. The unit cell parameters and volume are relatively reduced as compared to the values observed for polycrystalline $\mathrm{Pr}_{0.6} \mathrm{Sr}_{0.4} \mathrm{MnO}_{3}$ manganite elaborated by the solid state reaction [11]. 
The average crystallite size was evaluated from a width of diffraction peaks using Sherrer formula [14] and is found to be equal to $26 \mathrm{~nm}$.

\section{EMR results}

In Figure 2, we plot the electron magnetic resonance (EMR) spectra of the $\operatorname{Pr}_{0.6} \mathrm{Sr}_{0.4} \mathrm{MnO}_{3}$ recorded in the temperature range $200-370 \mathrm{~K}$. The maximum of intensity $\mathrm{I}(\mathrm{T})$ is observed at $\mathrm{T}=$ $250 \mathrm{~K}$. This temperature is lower than $315 \mathrm{~K}$ found for the $\operatorname{Pr}_{0.6} \mathrm{Sr}_{0.4} \mathrm{MnO}_{3}$ manganite elaborated by solid state method. In the paramagnetic phase the EMR spectrum consists of a single approximately symmetrical line with a shape close to a Lorentzian derivative. Using the EMR measurements the line width $\Delta \mathrm{H}$, the asymmetry, the intensity and the $\mathrm{g}_{\text {eff }}$ values were calculated. $\Delta \mathrm{H}$ is deduced from the peak-to-peak distance between the maximum and the minimum of the derivative of the EMR absorption, the asymmetry is defined by the maximum to minimum ratio. The intensity of the response is defined by $\beta(\Delta \mathrm{H})^{2}$, where $\beta$ is the peak amplitude. The $\mathrm{g}_{\text {eff }}$ value is determined via the following equation:

$$
\mathrm{g}_{\mathrm{eff}}=\mathrm{hv} / \mu_{\mathrm{B}} \mathrm{H}_{\mathrm{res}}
$$

where $h$ is the Planck constant, $\mu_{B}$ is the Bohr magneton, $v$ is the frequency and $H_{\text {res }}$ is the resonance field.

We should note that the resonance field diminishes slowly in the paramagnetic phase from 3366 Oe at $370 \mathrm{~K}$ down to $3348 \mathrm{Oe}$ at $200 \mathrm{~K}$. The similar behavior was reported by R. Thaljaoui et al. [11] for $\operatorname{Pr}_{0.6} \mathrm{Sr}_{0.4} \mathrm{MnO}_{3}$ manganite prepared by solid state reaction with mean crystallite size of $41 \mathrm{~nm}$.

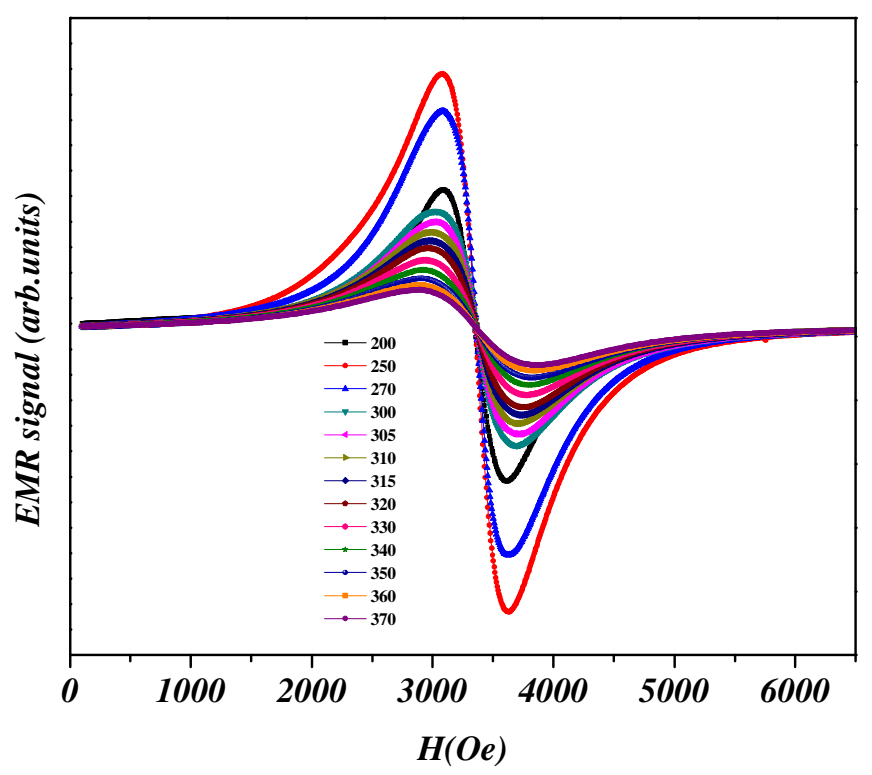

Fig. 2. Electron magnetic resonance spectra of $\mathrm{Pr}_{0.6} \mathrm{Sr}_{0.4} \mathrm{MnO}_{3}$ manganite

We plot in Figure 3 the temperature dependence of $\mathrm{g}_{\text {eff }}$. One may see that at $\mathrm{T}=370 \mathrm{~K}$ the corresponding value of $\mathrm{g}_{\text {eff }}$ is equal to 2.00054, which falls into a range characteristic for doped manganites in the paramagnetic state $[15,16]$. We should also note that the line width $\Delta \mathrm{H}$ is a non monotonic function of temperature (not plotted) for a broad temperature interval. The $\Delta \mathrm{H}$ exhibits a minimum at $310 \mathrm{~K}$. One may conclude that a transition temperature is located somewhat below $310 \mathrm{~K}$ as it is observed in manganites [11, 17]. 


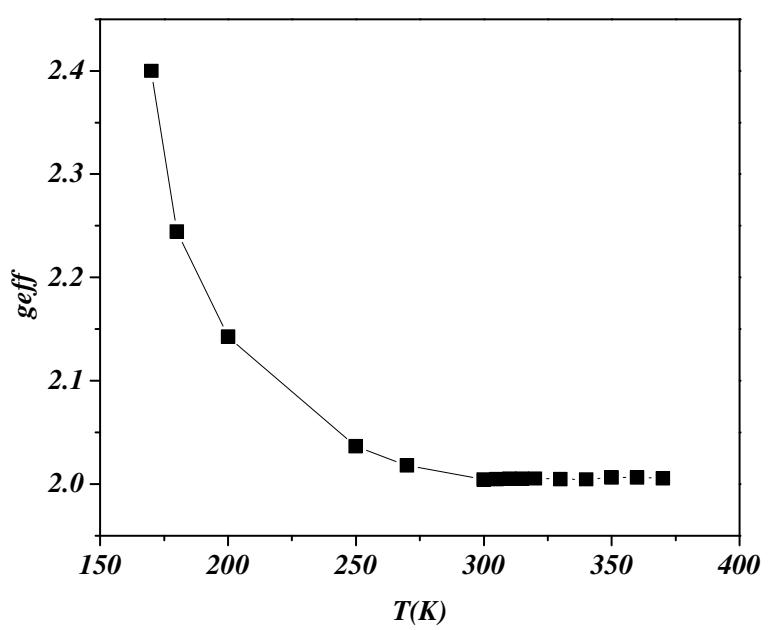

Fig. 3. Temperature dependence of $\mathrm{g}_{\text {eff }}$ of $\mathrm{Pr}_{0.6} \mathrm{Sr}_{0.4} \mathrm{MnO}_{3}$ manganite

Figure 4 shows the temperature variation of signal intensity $\mathrm{I}(\mathrm{T})$. In the ferromagnetic phase the signal intensity is an abruptly diminishing function of temperature. In the paramagnetic phase I(T) increases slowly. A similar behavior was observed for $\operatorname{Pr}_{0.6} \mathrm{Sr}_{0.4} \mathrm{MnO}_{3}$ manganite prepared by solid state reaction [11].

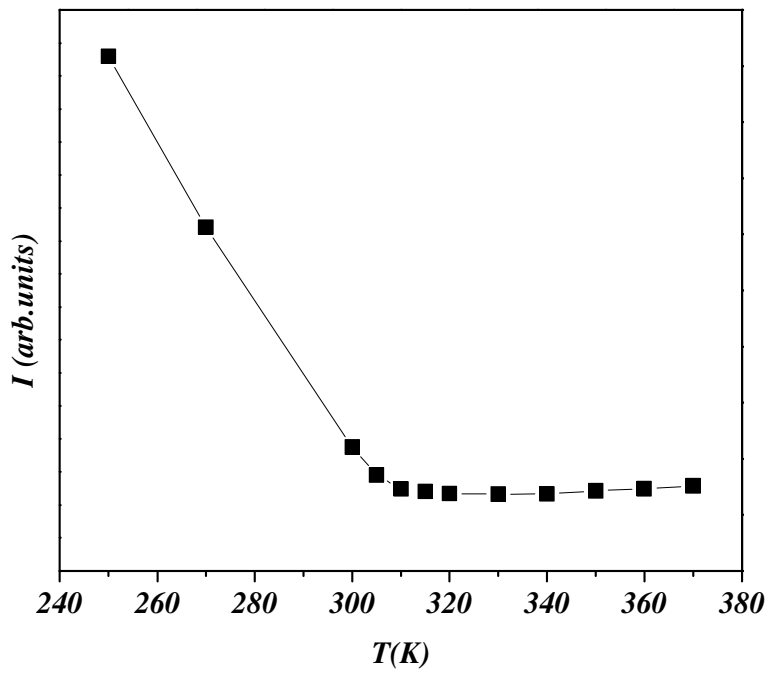

Fig. 4. Temperature dependence of signal intensity of $\mathrm{Pr}_{0.6} \mathrm{Sr}_{0.4} \mathrm{MnO}_{3}$ manganite

Above $250 \mathrm{~K}$ the intensity diminishes abruptly with temperature rising up to $310 \mathrm{~K}$, reaches a minimum and then increases slowly. One should notice that the accuracy of applied I (T) calculation is high enough only in paramagnetic phase, where signals are more symmetric (Figure 5). Therefore the $\mathrm{I}(\mathrm{T})$ dependence below $\mathrm{T}_{\mathrm{C}}$ offers only a rough approximation. In the paramagnetic phase the evolution of the signal intensity versus temperature can be expressed as follows:

$$
\mathrm{I}(\mathrm{T})=\mathrm{I}_{0} \exp \left(\mathrm{E}_{1} / \mathrm{k}_{\mathrm{B}} \mathrm{T}\right)
$$


where $\mathrm{k}_{\mathrm{B}}$ is the Boltzmann constant and $\mathrm{E}_{1}$ is the activation energy. The activation energy $\mathrm{E}_{1}$ equal to $67.6 \mathrm{meV}$ was deduced from $\mathrm{Ln}(\mathrm{I})$ versus $1 / \mathrm{T}$ dependence. Such activation energy is somewhat smaller than values reported for similar manganites [11].

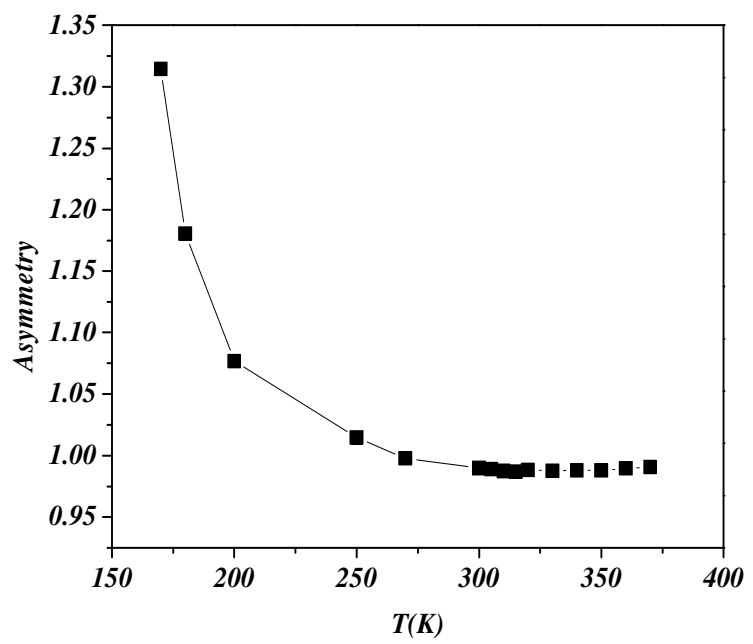

Fig. 5. Temperature dependence of signal asymmetry of $\mathrm{Pr}_{0.6} \mathrm{Sr}_{0.4} \mathrm{MnO}_{3}$ manganite

\section{Conclusions}

The structural study shows that our present sample crystallizes in the orthorhombic structure with Pnma space group and the mean crystallite size is about $26 \mathrm{~nm}$. Rietveld refinement indicates a decrease in the lattice volume of our sample compared to the manganite $\operatorname{Pr}_{0.6} \mathrm{Sr}_{0.4} \mathrm{MnO}_{3}$ prepared by solid state reaction.

The transition temperature is somewhat lower as compared to the $\operatorname{Pr}_{0.6} \operatorname{Sr}_{0.4} \mathrm{MnO}_{3}$ manganite prepared by the solid state method. It can be related to the influence of sol-gel method on grain size and its distribution. In the paramagnetic phase the EMR spectra consists of a single line with a shape close to a Lorentzian one and the resonance field corresponds to a geff factor close to 2 and is temperature independent.

\section{Acknowledgements}

This work was supported by the Tunisian Ministry of Higher Education and Scientific Research and the Ministry of Science and Higher Education of Poland.

\section{References}

1. A. M. Tishin, Y. I. Spichkin, The Magnetocaloric Effect and Its Applications, Institute of Physics, Bristol, 2003.

2. E. P. Nobrega, N. A. de Oliveira, P. J Von Ranke and A. Troper, J. Phys.: Condens. Matter 18 (2006) 1275-128.

3. X. X. Zhang, J. Taiada, Y. Xin, G. F. Sunm, K. W. Wong, X. Bohigas, Appl. Phys. Lett. 69 (1996) 3596.

4. Z. B. Guo, Y. W. Du, J. S. Zhu, H. Huang, W. P. Ding, D. Feng, Phys. Rev. Lett. 78 (1997) 1142 . 
5. C. N. R. Rao, B. Raveau (Eds.), Colossal Magnetoresistance, Charge Ordering and Related Properties of Manganese Oxides, World Scientific, Singapore, 1998.

6. P. K. Siwach, H. K. Singh, O. N Srivastava, J. Phys.: Condens. Matter 20 (2008) 273201.

7. R. N. Mahato, K. Sethupathi, V. Sankaranarayanan, R. Nirmala, J. Magn. Magn. Mater. 322 (2010) 2537.

8. D. H. Manh, P.T. Phong, T. D. Thanh, L.V. Hong, N. X. Phuc, J. Alloys Compd. 499 (2010) 131.

9. V. P. S. Awana, R. Tripathi, N. Kumar, H. Kishan, G.L. Bhalla, R. Zeng, L.S. Sharth Chandra, V. Ganesan, H.U. Habermeier, J. Appl. Phys. 107 (2010) 09D723.

10. P. G. Radaelli, M. Marezio, H.Y. Hwang, S.W. Cheong, J. Solid State Chem. 122 (1996) 444.

11. R. Thaljaoui, W. Boujelben, M. Pękała, J. Szydłowska, A. Cheikhrouhou, J. Alloys Compd. 526 (2012) 98.

12. H. M. Rietveld, J. App. Cryst. 2 (1969) 65.

13. T. Roisnel, J. Rodriguez-Carvajal, Computer program FULLPROF, LLB-LCSIM. May 2003.

14. A. Taylor, X-ray Metallography, Wiley, New York, 1961

15. C. Autret, M. Gervais, F. Gervais, N. Raimboux, P. Simon, Solid State Sciences 6 (2004) 815

16. J. Gutiérrez, V. Siruguri, J.M. Barandiarán, A. Peña, L. Lezama, T. Rojo, Physica B 372 (2006) 173.

17. T.L. Phan, N.D. Tho, L.V. Bau, N.X. Phuc, S.C. Yu, J. Magn. Magn. Mater. 303 (2006) e339e341 